\title{
EDUCAÇÃO PROFISSIONAL DE PESSOAS COM DEFICIÊNCIA NO BRASIL: MARCOS LEGAIS E REFLEXÕES ÉTICO-POLÍTICAS
}

\author{
PROFESSIONAL EDUCATION OF PEOPLE WITH DISABILITIES IN BRAZIL: LEGAL \\ BASES AND ETHICAL-POLITICAL REFLECTIONS \\ EDUCACIÓN PROFESIONAL DE PERSONAS CON DISCAPACIDAD EN BRASIL: \\ MARCOS LEGALES Y REFLEXIONES ÉTICO-POLÍTICAS
}

Carla Biancha Angelucci

E-mail: b.angelucci@usp.br

Fábia Carvalho de Oliveira

E-mail: fabia.co@gmail.com

Faculdade de Educação da Universidade de São Paulo

\begin{abstract}
RESUMO
A participação da pessoa com deficiência no mundo do trabalho constitui um campo de complexidades e desafios que compreende o estudo do mundo do trabalho na contemporaneidade e da educação e seus princípios, como a perspectiva inclusiva. Este ensaio se propõe a constituir um panorama da Educação Profissional destinada a pessoas com deficiência no Brasil, a partir de seus marcos legais. Ainda que a legislação brasileira garanta, há quase duas décadas, vagas para as pessoas com deficiência em empresas e que exista uma consequente demanda por esses trabalhadores/as, percebe-se a ausência dessa população nos espaços que oferecem educação profissional de nível técnico e também no mundo do trabalho. É possível afirmar que não há, no campo das políticas educacionais, programas interligados entre a educação especial e a educação profissional que fomentem a formação e o acesso das pessoas com deficiência para/ao o mundo do trabalho. E que há, portanto, um processo de invisibilização dessa parcela da população brasileira, que, alijada desses espaços, não encontra os meios de ter efetivado o seu direito à educação, tampouco a oportunidade de constituir-se pelo e para o trabalho.
\end{abstract}

PALAVRAS-CHAVE: A Educação Profissional. Educação Especial. Pessoa com Deficiência.

\section{ABSTRACT}

O resumo deve conter no máximo 15 linhas, formatação Times New Roman, tamanho 10, espaço 1,0 entre linhas, texto justifica The participation of people with disabilities in the labour field constitutes a field of complexities and challenges that includes Labour Studies in contemporary and educational fields and its principles, as the inclusive perspective. This essay proposes to constitute a panorama of the Professional Education destined to people with disabilities in Brazil, from its legal bases. Even though Brazilian legislation guarantees the legal reserve of positions for people with disabilities in companies for almost two decades, and there is a consequent demand for these workers, the absence of this population in spaces that offer Professional Education at a technical level is also evident. in the labour field. It is possible to affirm that in the working policies and in the special educations there are no interlinked programs between education and Professional Education that promote the training and access of people with disabilities to the labour field. And that there is, therefore, a process of invisibilization of this part of the Brazilian population, which, left over from these spaces, does not find the means to have its right to education fulfilled, nor the opportunity to constitute itself by and for work.

KEYWORDS: Professional Education. Special Education. Person with Disability.

\begin{tabular}{|l|l|} 
v.11 & n.3
\end{tabular}

p. $19-40$

Set./Dez. 


\section{RESUMEN}

La participación de la persona con discapacidad en el mundo del trabajo constituye un campo de complejidades y desafios que comprende el estudio del mundo del trabajo en la contemporaneidad y la educación y sus principios, como la perspectiva inclusiva. Este ensayo propone la constitución de un panorama de la Educación Profesional de las personas con discapacidad en Brasil, a partir de sus marcos legales. Aunque la legislación brasileña garantice, hace casi dos décadas, vacantes para las personas con discapacidad en empresas y que exista una consecuente demanda por esos trabajadores/as, es posible percibir la ausencia de esa población en los espacios que ofrecen educación profesional a nivel técnico y también en el mundo del trabajo. Es posible afirmar que no hay, en el campo de las politicas educativas, programas interconectados entre la educación especial y la educación profesional que fomenten la formación y el acceso de las personas con discapacidad hacia el mundo del trabajo. Por lo tanto, hay un proceso de invisibilización de esa parte de la población brasileña, que sigue aislada de los espacios sociales y laborales, pues que no encuentra los medios de haber efectuado su derecho a la educación.

PALABRAS-CLAVE: Educación Profesional. Educación Especial. Persona con Discapacidad.

\section{INTRODUÇÃ̃o}

Este ensaio trata da Educação Profissional de pessoas com deficiência no Brasil em sua interface com a Educação Especial. Para tanto, foi realizado levantamento da legislação dessas modalidades educacionais, bem como das políticas de acesso ao mundo do trabalho.

De acordo com o censo de Instituto Brasileiro de Geografia e Estatística de 2010 (IBGE, 2010), 48.606.048 brasileiros/as, ou seja, 23,9\% da população, têm algum tipo de deficiência - visual, auditiva, motora e mental ou intelectual. Destes/as, 24,94\% estão na faixa etária dos 15 aos 64 anos, o que seria considerada a idade produtiva.

A taxa de analfabetismo das pessoas que se declararam com ao menos uma das deficiências é de 9,3\% (BRASIL, 2012). O Censo Escolar/Ministério da Educação/Instituto Nacional de Estudos e Pesquisas Educacionais Anísio Teixeira - Censo Escolar MEC/INEP , registra, em 2015, o quantitativo de quase 800 mil estudantes do público-alvo da Educação Especial matriculados/as em classes comuns na Educação Básica e algo em torno de 180 mil estudantes em classe ou escolas especiais (BRASIL, 2016).

No Ensino Médio, comparando os anos de 2003 e 2015, há um aumento do número de matrículas de estudantes com deficiência de 1.007\%, de acordo com o Censo Escolar MEC/INEP.

Na Educação Profissional, as informações sobre as matrículas de estudantes públicoalvo da Educação Especial começaram a ser registradas em 2009 e, desde esse período, já registram um aumento de 295\%: em 2009 havia pouco mais de 700 estudantes em classes comuns e, em classes ou escolas especiais, pouco mais de mil estudantes. Já em 2015, o 
Censo registra seis mil estudantes em classes comuns e pouco mais de mil em escolas ou classes especiais (BRASIL, 2016).

Do ponto de vista da legislação brasileira e das políticas públicas voltadas para essa população, poder-se-ia considerar o cenário favorável. Contudo, parcela significativa de pessoas com deficiência segue fora do mundo do trabalho, sendo inúmeras as hipóteses de compreensão do fenômeno, entre elas, a falta de políticas de educação para o trabalho, a persistência do estigma de incapacidade que ainda pesa sobre as pessoas com deficiência, a inadequação das várias dimensões da acessibilidade (comunicacional, atitudinal, arquitetônica, etc.) desse setor populacional aos processos de trabalho (CLEMENTE, 2015).

Nesse sentido, discutir as categorias trabalho, educação e deficiência no contexto das políticas públicas, bem como as concepções que produzem o contexto histórico, econômico e social vigente poderá fornecer elementos importantes para uma reflexão sobre a temática proposta.

\section{REFERENCIAL TEÓRICO}

\section{Trabalho, educação e deficiência}

A educação e o trabalho são direitos fundamentais, garantidos em lei e estendem-se a todas as pessoas, sem distinção, conforme o artigo $6^{\circ}$ da Constituição Federal de 1988. A educação é um direito inalienável, universal e fundamental, pois garante viabilidade para que outros direitos se realizem. Garante também o acesso ao patrimônio cultural de forma sistematizada e intencional; a participação social; a formação para o trabalho e amplia as possibilidades de participação ativa no mundo. O trabalho, por sua vez, possibilita à pessoa com deficiência a geração de renda, a independência, a transformação da realidade e, com isso, a ocupação do lugar social de adulto/a.

O trabalho pode ser tomado como um elemento definidor de muitos aspectos das relações econômicas e políticas das sociedades capitalistas pós Revolução Francesa, com repercussões no modo como são constituídas as relações com a propriedade privada e a venda da força de trabalho para a fonte da mais-valia.

Situar essa categoria no contexto das relações produtivas e no modo como a sociedade se organiza ajuda a refletir sobre a produção das concepções de educação profissional ao longo do tempo. São esses subsídios que permitem problematizar que tipo de educação 
profissional é ofertada, qual a visão acerca do trabalho as constitui e, consequentemente, quais são os sentidos da oferta de educação Profissional para as pessoas com deficiência.

Nesse sentido, foi tomado, em Marx, o conceito de trabalho para, a partir dessa abordagem, lançar o aporte da discussão. Para Marx, o trabalho seria

(...) atividade orientada a um fim para produzir valores de uso, apropriação do natural para satisfazer as necessidades humanas, condição universal do metabolismo entre o homem e a Natureza, condição natural eterna da vida humana e, portanto, independente de qualquer forma dessa vida, sendo igualmente comum a todas as suas formas sociais (MARX, 1998, apud LANCILLOTTI, 2013, p. 52).

Assim, o objetivo do presente artigo é discutir a política brasileira de Educação Profissional de pessoas com deficiência. Para tanto, inicialmente, será analisada a Educação Profissional no Brasil. A seguir, serão apresentadas considerações sobre a educação de pessoas com deficiência no país, para, então, retomar os marcos legais da Educação Profissional de pessoas com deficiência. Tal quadro permitirá a reflexão sobre os aspectos ético-políticos envolvidos na temática.

\subsection{A política de educação profissional - alguns princípios}

A política brasileira de educação profissional refletiu, ao longo da história, as tensões que permeiam o campo discursivo da finalidade da formação profissional perante as transformações dos modos produtivos e o avanço das lutas de classes tão próprias de uma sociedade baseada no capital. Portanto, impossível não traçar um paralelo entre as discussões a respeito do lugar que o trabalho ocupa na sociedade e os reflexos desse posicionamento na elaboração das políticas públicas brasileiras de educação profissional.

Del Pino (2001), discutindo a reforma educacional brasileira dos anos de 1990, aborda a questão da formação profissional, por vezes apontada como a resposta necessária frente aos desafios impostos pelas transformações dos modos produtivos e do mundo do trabalho, e como importante estratégia para lidar com o desemprego estrutural. Para alguns/algumas autores/as, a educação básica e a formação profissional baseadas nos avanços científicos e tecnológicos, poderiam permitir aos países em situação de dependência econômica, a participação no processo de restruturação produtiva e globalização. Entretanto, a realidade do mundo do trabalho mostra que a qualificação profissional não garante a inserção da classe trabalhadora, mas que é a flexibilização das relações de trabalho o principal movimento do 
sistema produtivo, permitindo a contratação de trabalhadores/as com baixa qualificação, submetidos a situações de precarização, e não há, portanto, a efetiva criação de mais postos de trabalho. Ainda assim, a formação profissional tem sentido os impactos destas transformações do mundo produtivo. E a resposta dos sistemas de educação profissional frente à restruturação do processo produtivo evidencia a importância de se ajustar a força de trabalho às exigências do mercado. $\mathrm{O}$ autor enfatiza, no entanto, que a formação profissional tem de ser tratada como uma questão política e social, que se leve em conta as tensões que permeiam as lutas de classes, a desigual distribuição dos recursos materiais, e não apenas como uma questão técnica, sob a égide do pensamento neoliberal para o qual os problemas educacionais são tratados como “questões de eficácia/ineficácia na gerência e administração dos recursos humanos e materiais" (DEL PINO, 2001, p.77).

Oliveira (2015) acrescenta a essa discussão que a adoção da chamada 'pedagogia das competências' como base dos processos formativos da educação profissional reafirma a estruturação do campo da educação profissional de acordo com as diretrizes do campo econômico. Assim como o Brasil, as nações latino-americanas tomaram por referência as orientações de organizações econômicas internacionais, como o Banco Mundial e o Branco Interamericano de Desenvolvimento (Bird) para a elaboração de seus projetos educacionais.

Buscando ampliar a inserção dos/as trabalhadores/as, o discurso em defesa da empregabilidade via qualificação profissional carrega em si a ideia de que a baixa qualidade da mão de obra decorre da fragilidade da educação pública e profissional, em lugar de lançar o olhar para a situação de exploração econômica a qual os países mais pobres são historicamente submetidos. Para Oliveira (2015, p. 249),

A forma de participação de cada nação na divisão internacional do trabalho determinará a necessidade e a pertinência da existência de maior estoque de mão de obra qualificada para a produção de bens com maior valor agregado. Não é o processo de formação de capital humano o responsável, em primeira instância, por essa inserção, e muito menos a inserção como protagonista constrói-se desconsiderando relações de poder condicionantes das formas de participação de algumas economias nacionais no processo de mundialização do capital.

As práticas de Educação Profissional adequam-se à lógica do capital, pois tratam de conformar os/as trabalhadores/as às necessidades do mercado, cuja demanda crescente por mão de obra para postos de trabalho precarizados justificaria as políticas de formação profissional associadas à situação precária da escola pública e à baixa qualidade da educação 
ofertada, permitindo concluir que tal situação estaria a serviço do processo de reprodução da sociedade capitalista e ampliação dos processos de exploração de trabalhadores/as.

No Brasil, a elaboração e a implementação das políticas públicas de Educação Profissional seguiram um caminho de contradições e litígios, constituindo um jogo de forças entre sociedade, mercado e Estado, sendo desconsiderada boa parte das discussões produzidas pela Academia sobre a Educação Profissional frente aos desafios, disputas e possibilidades desta modalidade educacional. Essas discussões acompanharão, no próximo tópico, a descrição da política de Educação Profissional brasileira atual, bem como os programas vigentes.

\subsection{A educação profissional no Brasil}

No Brasil, a Educação Profissional é parte dos diferentes níveis e modalidades de Educação, ligando-se às dimensões do trabalho, da ciência e da tecnologia. As reformulações impostas à Educação Profissional ao longo da história apontam para as adequações dessa modalidade aos movimentos discursivos contemporâneos.

Formulada a partir do estabelecido nos artigos 36 e 39 a 42 da Lei ${ }^{\circ} 9.394 / 1996$ (Ldben) e, posteriormente regulamentada pelo Decreto $\mathrm{n}^{\circ}$ 2.208, de 17 de abril de 1997, a Educação Profissional prevista nessa legislação baseava-se em uma concepção dissociada da Educação Básica, resultando numa formação técnica modular e superficial (MEC, 2005). Del Pino (2001) ressalta que essa reformulação estava de acordo com as ideias neoliberais tão presentes nas políticas de educação, resultando na abertura de "espaços necessários para a institucionalização, novamente, da dualidade estrutural na educação brasileira, através da pulverização de políticas e sistemas de ensino" (p.78). Em decorrência da reformulação, a estrutura das escolas técnicas e agrotécnicas federais foi modificada, como também uma série de cursos técnicos tradicionais foram extintos. A separação do Ensino Médio da Formação Técnica, o ponto central da reformulação, contribuiu indubitavelmente para distanciar a escola do mundo do trabalho, resultando na expressiva aproximação da escola a uma concepção capitalista da educação. Silva (1993) apud Del Pino (2001, p.78) afirma que "a escola no capitalismo é capitalista porque é separada da produção. Ela é capitalista não por causa de seus efeitos individuais, mas essencialmente por sua posição estrutural de separação em relação à produção." 
Outra observação importante feita pelo autor são os instrumentos legais empregados para essa reformulação, qual sejam, Medida Provisória, Decreto Presidencial e Portaria Ministerial. Esse dado torna-se mais relevante ainda tendo em vista a recorrência com que esses instrumentos antidemocráticos são empregados para definir e redefinir os rumos da educação brasileira. Vide a reformulação do Ensino Médio em curso em 2017.

Em 2004, por meio do Decreto $\mathrm{n}^{\circ} 5.154$, de 22 de julho de 2004, foi revogado o Decreto $n^{\circ}$ 2.208/1997 e restabeleceu-se assim a possibilidade de integração curricular do ensino médio e ensino técnico. Este novo decreto previu o estabelecimento de novas diretrizes para a educação profissional, por meio de um amplo debate que envolveria os sistemas de ensino, as instituições e os docentes (FRIGOTTO et alli, 2005). Contudo, a criação e implementação de uma nova organização para a educação não significaram avanços na educação profissional brasileira com relação às políticas anteriores.

Frigotto et alli (2005) analisam as contradições presentes no processo de implementação das políticas públicas de educação profissional no primeiro do governo Lula (de 2001 a 2005), apoiados no pressuposto de que uma mudança estrutural da sociedade brasileira é um processo lento, e que expressa "a natureza das relações de poder das classes sociais". O caminho escolhido - a revogação de um Decreto e instituição de outro, em lugar de retomar o debate sobre a Lbden - é marcado pela adoção de medidas contingenciais e programas pontuais, tornando a política de educação profissional repleta de contradições e intensos conflitos.

\subsection{Organização da educação profisssional no Brasil}

A Secretaria de Educação Profissional e Tecnológica do Ministério da Educação (Setec/MEC) coordena a política de educação profisssional e tecnológica é responsável pela organização da educação profissional, conforme a legislação vigente. As atribuições da Setec foram atualizadas por meio do Decreto $\mathrm{N}^{\circ}$ 9.005, de 14 de março de 2017.

O Decreto $\mathrm{n}^{\circ} 1.514 / 2004$ estabelece três níveis de classificação da modalidade: formação inicial e continuada de trabalhadores/as, educação profissional técnica de nível médio e educação profissional tecnológica de graduação e de pós-graduação. De acordo com o artigo $3^{\circ}$,

[...] os cursos de formação continuada (...) incluídos a capacitação, o aperfeiçoamento, a especialização e a atualização, em todos os níveis de 
escolaridade, poderão ser ofertados segundo itinerários formativos, objetivando o desenvolvimento de aptidões para a vida produtiva e social (BRASIL, 2004).

A articulação entre a Educação Profissional e o Ensino Médio, principal premissa da atual legislação, é proposta a partir da oferta da modalidade de forma integrada para os/as estudantes que concluíram o ensino fundamental, a fim de que recebam uma habilitação profissional técnica de nível médio, na mesma instituição de ensino, contando com uma única matrícula. E de forma concomitante, para os/as estudantes que já concluíram o Ensino Fundamental ou que estejam cursando o Ensino Médio, em uma perspectiva de complementaridade, prevendo matrículas distintas para cada curso (BRASIL, 2004; CASTIONI, 2010).

Os principais decretos que dispõem sobre a estrutura da Educação Profissional, com base nessa nova perspectiva, foram publicados nos anos seguintes e instituíram os programas de maior impacto na oferta da educação profissional.

A Lei $n^{\circ} 11.741$, de 16 de julho de 2008 modificou os artigos 39 a 42 da Ldben, que versam sobre a Educação Profissional. O capítulo que trata desse tema passa a ser intitulado "Educação Profissional e Tecnológica", incluindo aí o que foi estabelecido pelo Decreto 5.154/2004 com relação à oferta da educação profissional.

O governo federal, por meio da Lei 12.513, de 26 de outubro de 2011, criou o Programa Nacional de Acesso ao Ensino Técnico e Emprego (Pronatec), com a finalidade de "ampliar as oportunidades educacionais e de formação profissional qualificada aos jovens, trabalhadores e beneficiários de programas de transferência de renda", por meio da oferta de cursos de educação profissional e tecnológica (BRASIL, 2011). A proposta do Pronatec é de articulação com outros programas da Secretaria de Educação Profissional e Tecnológica, atuando em conformidade com o atual Plano de Desenvolvimento da Educação - PDE (BRASIL, 2007), com o Plano Nacional de Educação 2011-2020 e com as Diretrizes Curriculares Nacionais para Educação Profissional de Nível Médio, que, na ocasião da aprovação do Pronatec, ainda estavam em fase de discussão (GODOI, 2014).

As atuais Diretrizes Curriculares Nacionais para a Educação Profissional Técnica de Nível Médio foram definidas pela Resolução ${ }^{\circ} 6$ de 20 de setembro de 2012 e o texto final dessas diretrizes representa o produto de uma série de discussões promovidas no âmbito do MEC, Conselho Nacional de Educação (CNE) e Câmara de Educação Básica (CEB), tendo 
recebido contribuições dos meios acadêmico, profissional e sindical, das instituições públicas de ensino, pesquisadores e gestores da educação profissional e tecnológica.

A política de Educação Profissional foi construída em um território de disputas, com concepções políticas diferenciadas, sobretudo no que diz respeito à integração da formação profissional ao Ensino Médio. As consequências desse modo de construir a política pública para a formação integral dos/as estudantes podem ser percebidas na produção legal que acompanha a política (GODOI, 2014).

Ao analisar as políticas públicas de qualificação profissional dos últimos anos e seus impactos sobre a inserção de jovens no mercado de trabalho, Oliveira (2015) aponta que

[...] as políticas públicas de qualificação profissional, particularmente as voltadas para a juventude, ampliadas no mandato do presidente Lula e continuadas no governo Dilma, ao pautarem-se pelo desenvolvimento de competências laborais, pelo fortalecimento da empregabilidade e pelo objetivo de formar sujeitos empreendedores, reforçam a ideologia da meritocracia, bem como individualizam o enfrentamento ao problema do desemprego, retirando do Estado o compromisso social e político de enfrentamento à lógica desestruturante do capital (OLIVEIRA, 2015, p.246).

O autor constrói sua argumentação a partir de dados apresentados pelo Ministério do Trabalho e Emprego (MTE) e do Departamento Intersindical de Estatística e de Estudos Socioeconômicos (Dieese) e faz correlações com os programas de qualificação profisssional que não conseguem dar conta de uma formação profissional mais completa, pois encontra entraves importantes diante de uma formação precária dos/as jovens no âmbito da Educação Básica. Aponta ainda que é dada maior importância à certificação rápida, prejudicando a qualidade da formação. As consequências desse modo de conceber a formação profissional é o que Kuenzer (2007) chama de "inclusão excludente", um sistema que produz desigualdades sociais, ao mesmo tempo em que se estrutura a partir delas. Assim, os/as estudantes pobres abandonam a escola pública precocemente e, em busca de trabalho, ingressam nos programas de qualificação profissional para obterem certificação ou conhecimentos necessários para o imediato acesso ao mundo do trabalho. Como aponta Kuenzer,

A estratégia por meio da qual o conhecimento é disponibilizado/negado, segundo as necessidades desiguais e diferenciadas dos processos de trabalho integrados, é o que temos chamado de inclusão excludente na ponta da escola. Ao invés da explícita negação das oportunidades de acesso à educação continuada e de qualidade, há uma aparente disponibilização das oportunidades educacionais, por meio de múltiplas modalidades e diferentes naturezas, que se caracterizam por seu caráter desigual e, na maioria das

\begin{tabular}{|l|l|}
\hline v.11 & n.3 \\
\hline
\end{tabular}


vezes, meramente certificatório, que não asseguram domínio de conhecimentos necessários ao desenvolvimento de competências cognitivas complexas vinculadas à autonomia intelectual, ética e estética (KUENZER, 2007, apud OLIVEIRA, 2015, p.259)

As críticas à política de Educação Profissional são contundentes e importantes, pois afirmam que as forças conservadoras em favor do capital disputam com as forças progressistas que buscam, legitimamente, a emancipação da classe trabalhadora, tornando este um campo minado. E é preciso admitir que um dos lados conta com um aparato ideológico, político e econômico que garante sua supremacia frente aos apelos de uma sociedade mais justa. Todavia, há forças de resistências que residem na discussão potente que busca trazer para os diferentes espaços o ideário de uma Educação Profissional comprometida com a formação integral dos sujeitos.

\section{RESULTADOS}

\section{Interfaces das políticas de Educação Especial e Educação Profissional}

A Educação Profissional da pessoa com deficiência - tema deste ensaio - foi examinada nas principais publicações ligadas à educação especial e à educação profisssional. Nelas, há menção ao acesso da pessoa com deficiência aos processos educativos para o mundo do trabalho, como uma garantia constitucional, um desdobramento do direito à educação. Contudo, a busca por políticas públicas ou programas específicos de formação profissional para o público-alvo da educação especial não produziu resultados expressivos. Dentre os documentos oficiais do MEC, há apenas um que trata especificamente da questão. É um documento de 2003 e representa um importante marcador para a interface da Educação Especial com a Educação Profissional. A seguir, serão apresentados aspectos gerais desse documento, bem como as Resoluções, os Programas e as Notas Técnicas que relacionam a educação especial à educação profissional.

Em 2003, a então Secretaria de Educação Especial do MEC apresentou o documento "Indicações para Ação: A Interface Educação Profissional/Educação Especial”, com o objetivo de orientar gestores/as e profissionais da educação na "elaboração de propostas pedagógicas para a educação profissional de pessoas com necessidades educacionais especiais", propondo às instituições escolares "novas modalidades de ação (...) em uma perspectiva emancipadora, que atenda aos interesses sociais e propicie a implementação de 
uma política de Educação Profissional" (Brasil, 2003). O documento ressalta que, para o desenvolvimento do programa de Educação Profissional, a parceria entre as instituições de ensino, de trabalho e os setores empresariais é fundamental. Contudo, o documento é destinado aos/às professores/as.

É importante destacar que o documento foi elaborado tendo por base o Plano Nacional de Educação, elaborado a partir do que foi preconizado na Ldben de 1996, recém aprovada à época. E que, nesse momento, estava em vigor o Decreto 2.208/1997, que regia a educação profissional na perspectiva da "trabalhabilidade" (diz respeito à capacidade de resposta do trabalhador nos quesitos eficiência, eficácia e efetividade) e "empregabilidade" (o/a trabalhador/a ter condições de pleitear um posto de trabalho e permanecer nele).

Para a intersecção da Educação Especial com a Educação Profissional, o documento aponta para a necessidade de apropriar-se da noção de educação inclusiva e de operacionalizala nos vários níveis da educação profisssional. Essa operacionalização partiria da construção de uma "resposta institucional" à questão "Quem é o sujeito, não do ensino, mas da aprendizagem?", pergunta baseada na perspectiva de Ortega e Gasset, que apontam $o$ "aluno e a sua circunstância", (ou sua diversidade) como o tal sujeito. De acordo com o documento,

À instituição escolar cabe desenvolver, a partir dos marcos legais existentes e dos ordenamentos jurídicos legais disponíveis, propostas e níveis de acessibilidade capazes de viabilizar a prática de uma educação inclusiva, a partir de quatro diferentes níveis: Currículo (...); Gestão (...); Metodologias (...) e Avaliação (...) (BRASIL, 2003).

E ainda acrescenta que as instituições de educação profissional adotem, na sua programação de cursos, a ideia da "pluritemporalidade", como forma de acolher os/as estudantes com deficiência (referidos no documento como "alunos com necessidades educacionais especiais"), o que implica em "compreender os diversos tempos do aluno. Aprender, curricularmente, a dimensão provisória do saber organizado. Irromper o conceito físico de tempo e enraizar a aprendizagem nas circunstâncias plurais de cada um" (BRASIL, 2003, p.26).

Quanto aos aspectos relacionados à aprendizagem dos estudantes, o documento aponta para um compromisso da escola com a dimensão social da aprendizagem, permitindo assim que a "evolução cognitiva" dos/as estudantes se constitua por meio da abordagem contextualizada do conhecimento, com o foco na construção identitária. Para atender a essa orientação, o documento lista várias ações, dentre as quais destacam-se: o trabalho com 
programas flexíveis, para que atendam às diversidades do público-alvo; a utilização de metodologias "multidiretivas" para a abordagem do conteúdo; a percepção da escola como espaço de construções diversas que acontecem a partir de diferentes configurações dos processos formativos; e inclusão dessas perspectivas nos projetos pedagógicos da escola.

Pode-se perceber que em todo o documento há a preocupação em superar a ideia de impossibilidade que acompanha os/as estudantes com deficiência, propondo, portanto, considerar os "desafios epistemológicos" contidos na categoria conceitual "alunos com necessidades educacionais especiais", que implica em reconhecer a polissemia do termo 'especial'. Trata-se de considerar que o termo engloba as ideias de uma diversidade de necessidades, de limites e de projetos que, balizados nos marcos legais, devem ser considerados no momento em que são elaborados os programas de educação profissional, a fim de garantir a plena acessibilidade formativa a esse público. O texto ainda aponta que os programas e cursos "devem resultar da construção de consensos políticos-pedagógicos entre redes de apoio à sustentabilidade do processo inclusivo", considerando que os campos de gestão, de currículos, metodológico, dos docentes, da avaliação, dos recursos técnicos e financeiros, precisam ser discutidos e reorganizados, com o objetivo de construir as diretrizes que apontariam a intencionalidade da ação inclusiva. De acordo com texto, a organização e a oferta desses programas devem ainda atender aos seguintes critérios:

1. A escola precisa abandonar a visão circunstancial do "especial" como um problema intransponível na sala de aula.

2. O aluno "especial" deve ser enxergado como detentor de uma cidadania em construção. Isto implica em the possibilitar o desenvolvimento de competências e habilidades individuais que lhe assegurem autonomia de movimentos e meios de ele se afirmar socialmente.

3. Cada escola, enquanto Centro de Referência, deve abrir-se s questões de pertinência institucional e montar (conceber, organizar e executar) uma AGENDA que defina: I- Atividades - Que programas vamos oferecer? IIVinculações - Quem vai trabalhar (instituição) e com que vamos trabalhar (alianças estratégicas)? III- Ambivalências - Onde vamos trabalhar? IVMetodologias - Como vamos trabalhar? V- Meios e recursos - De que vamos precisar? VI- Aferição de resultados - Como vamos avaliar? VII- Cronograma - Quando vamos executar? VIII-Relatórios de progresso - Que etapas devem ser definidas como indicadoras de efetividade? (BRASIL, 2003).

Essas ações permitirão que o/a estudante avance na construção da sua individualidade, permitindo o desenvolvimento de habilidades e competências individuais que proporcionem 
"autonomia para viver sua vida, realizando atividades laborais e trabalhos compatíveis com as suas singularidades" (Brasil, 2003).

Os modelos e a oferta dos cursos de Educação Profissional, de nível básico e nível médio, devem levar em consideração as orientações contidas na legislação, na qual estão previstas possibilidades de uma organização flexível, levando em conta a realidade das instituições e as demandas dos estudantes com deficiência, cujo acesso e permanência deverão ser garantidos por meio de "arranjos organizacionais" das condições estruturais da instituição, ou relacionadas à formação do corpo docente.

O documento apresenta um capítulo que trata do desafio que é a formação do/a professor/a da educação profissional que atuará com o/a estudante com deficiência, frente as particularidades que acompanham a formação docente, na perspectiva de favorecer a progressão das aprendizagens desses/as estudantes por meio das atividades desenvolvidas. Para a capacitação desse/a docente, sugere que a formação se estruture nas seguintes etapas, denominadas "blocos de formação para o trabalho pedagógico":

Sobre a formação docente dos/as professores/as das Oficinas Pedagógicas e daqueles/as que atuarão na Rede Federal de Educação Tecnológica/Centros de Referência, o documento ainda aponta orientações específicas. Os conteúdos, ou dimensões metodológicas dessa formação são descritos no documento e objetivam capacitar o/a docente para que

[...] domine bem os conhecimentos com que trabalha ou vai trabalhar, tenha as habilidades indispensáveis à organização e transmissão destes conhecimentos e, por fim, seja capaz de, no caso de trabalho com alunos com deficiência, conhecer-lhes as particularidades educacionais, suas potencialidades e necessidades específicas (BRASIL, 2003).

Quanto aos aspectos relacionados à avaliação, essa formação docente propõe uma mudança no enfoque da avaliação para 'avaliações baseadas em escalas diferenciadas', a fim de garantir que as práticas pedagógicas inclusivas considerem "as formas inovadoras de trabalhar a aprendizagem e os mecanismos criativos de integração escolar e social de contingentes específicos de alunos". Portanto, a formação teria por objetivo fornecer aos/às professores/as subsídios para articular suas práticas pedagógicas ao princípio da inclusão, considerada na sua concepção mais concreta - a da ação educativa inclusiva.

A quinta parte do documento traz uma importante reflexão sobre os desafios da implementação de uma política de educação profissional para o público da educação especial. A sexta parte do documento apresenta uma proposta de "ressignificação" das Oficinas 
Pedagógicas. Traz uma série de orientações que inclui os objetivos, as recomendações para o uso de instrumentos de acompanhamento e avaliação de desempenho dos estudantes que estão nos programas de educação profissional, o modo de funcionamento dessas oficinas e ainda as recomendações para a construção de uma proposta pedagógica individualizada para os estudantes. Os modelos das fichas, ou instrumentos de acompanhamento, estão anexados ao documento. Essa parte do documento é bastante importante, pois as Oficinas Pedagógicas constituem, ainda hoje, a principal modalidade de atendimento nas instituições conveniadas ou públicas que atendem a grande parte do público da educação especial.

Sobre as recomendações para o uso dos instrumentos de acompanhamento e avaliação do desempenho do/a estudante, o documento indica a sua importância para a construção do Plano de Individualizado de Aprendizagem para os/as estudantes, que dará subsídios para a inserção do/a estudante no mundo do trabalho.

As Oficinas Pedagógicas são destinadas aos/às estudantes com deficiência 'mental' e múltipla, com mais de 14 anos, nas "Escolas Especiais Governamentais e Não Governamentais". Estes/as estudantes permanecerão nessas oficinas até que sejam avaliados/as por uma equipe 'interprofissional' e poderão ser encaminhados/as aos cursos de qualificação profissional, desde que atendam aos requisitos ou definições normativas dos sistemas para os quais pleiteiam o acesso.

A parte final do documento constitui-se de "Orientações básicas para o encaminhamento à segunda etapa da Educação Profissional”. É composta de uma série de recomendações e estratégias de 'colocação' dos/as estudantes no mundo do trabalho. Essas ações são de responsabilidade das instituições que oferecem a Educação Profissional.

Destaca-se que esse documento representa uma importante iniciativa de discutir a educação profissional das pessoas com deficiência e, mesmo que suas bases legais, educacionais, e com relação à pessoa com deficiência estejam datadas, a perspectiva central do documento pauta-se no potencial de aprendizagem dos/as estudantes e na necessidade de pensar a formação a partir da ressignificação das práticas pedagógicas pelas instituições de educação profissional.

A busca da intersecção entre a Educação Profissional e a educação especial realizada no curso deste trabalho, constituiu-se da leitura atenta de toda legislação e, também, de resoluções, programas educacionais, políticas de educação profissional, dentre outros. 
A Resolução do CNE/CEB n 6, de 20 de setembro de 2012, define Diretrizes curriculares nacionais para a Educação Profissional Técnica de nível médio. Aponta, dentre os princípios norteadores da educação profissional, o "reconhecimento dos sujeitos e suas diversidades, considerando, entre outras, as pessoas com deficiência, transtornos globais do desenvolvimento e altas habilidades (...)" (BRASIL, 2012). A previsão da oferta dos cursos de Educação Profissional Técnica de nível médio ocorreria mediante projeto pedagógico unificado, de acordo a diretriz que visa articular os objetivos dos sistemas de ensino à educação profissional. Sendo assim, estes cursos "devem atender às diretrizes e normas nacionais definidas para a modalidade específica, tais como (...) Educação Especial" (BRASIL, 2012). E não há outras referências para a formação profissional da pessoa com deficiência, tampouco, diretrizes específicas para o público-alvo da educação especial.

Quanto ao Pronatec, há na lei que o define menção ao atendimento às pessoas com deficiência no artigo $2 .^{\circ}, 2^{\circ}$ parágrafo:

Será estimulada a participação das pessoas com deficiência nas ações de educação profissional e tecnológica desenvolvidas no âmbito do Pronatec, observadas as condições de acessibilidade e participação plena no ambiente educacional, tais como adequação de equipamentos, de materiais pedagógicos, de currículos e de estrutura física. (BRASIL, 2011).

Em relação ao Programa Bolsa-Formação, uma das ações previstas do Pronatec, cabe destacar que havia previsão de estimulo à participação das pessoas com deficiência, que também teriam atendimento preferencial nos cursos de Formação inicial e continuada (FIC) e de técnicos concomitantes, ofertados por meio da Bolsa-Formação. As instituições ofertantes dos cursos deveriam promover a acessibilidade a essas pessoas, observar "as condições de participação plena no ambiente educacional, tais como adequação de equipamentos, de materiais pedagógicos, de currículos e de estrutura física”. (BRASIL, 2015). A oferta de cursos a distância, por meio da Bolsa-Formação "desenvolverá ações de apoio à expansão da oferta, por meio de (...) V - desenvolvimento de ações, propostas e projetos voltados à acessibilidade de estudantes com necessidades especiais à EaD” (BRASIL, 2015).

A Consolidação da Inclusão Escolar no Brasil (BRASIL, 2016), ao mencionar a Política Nacional de Educação Especial na Perspectiva da Educação Inclusiva, reafirma a importância do atendimento educacional especializado no apoio ao desenvolvimento dos estudantes também na educação profissional, pois "as ações da educação especial possibilitam a 
ampliação de oportunidades de escolarização, formação para ingresso no mundo do trabalho e efetiva participação social" (BRASIL, 2016).

Em busca de outras menções à educação profissional articulada à educação especial na publicação, uma pesquisa empreendida nos documentos elencados nela, apontam os seguintes resultados:

- A Nota Técnica $\mathrm{n}^{\mathrm{o}}$ 055, de 10 de maio de 2013 (MEC/ Secadi/ Dpee), refere-se à Orientação à atuação dos Centros de AEE, na perspectiva da educação inclusiva, e versa sobre a construção do Projeto Político Pedagógico (PPP) dos Centros de Atendimento Educacional Especializado, que deve considerar "a transversalidade da educação especial nas diversas etapas e modalidades de ensino; a colaboração em redes de apoio à inclusão, visando o acesso a serviços, recursos, profissionalização, trabalho, dentre outros" (BRASIL, 2013).

- A Nota Técnica $n^{\circ}$ 101, de 12 de agosto de 2013, (MEC/ Secadi/ Dpee), refere-se a Política de Educação Especial na Perspectiva Inclusiva e traz alguns resultados da implementação desta política. No que concerne à educação profissional da pessoa com deficiência, a Nota cita o Pronatec e a meta do programa de ofertar 150 mil vagas para pessoas com deficiência e confirma um total de 4 mil matrículas de pessoas com deficiência (BRASIL, 2013).

- A Nota Técnica n $^{\circ} 106$ de 19 de agosto de 2013, (MEC / SECADI / DPEE) traz a Orientação à Implementação da Política Institucional de Acessibilidade na Rede Federal de Educação Profissional, Científica e Tecnológica, e tem por finalidade "ressaltar as condições necessárias para o pleno acesso, participação e aprendizagem dos estudantes com deficiência, à Educação Profissional e Tecnológica”. As instituições da Rede Federal de Educação Profissional, Científica e Tecnológica, devem "assegurar o pleno acesso, em todas as atividades acadêmicas”. A nota também traz toda a legislação sobre a educação da pessoa com deficiência, o Atendimento Educacional Especializado (AEE), e também as iniciativas quanto à formação profissional da pessoa com deficiência, dentre as quais, destacamos a Lei ${ }^{\circ} 11.892$, de 29 de dezembro de 2008, que institui a Rede Federal de Educação Profissional Científica e Tecnológica.

Essa nota técnica, dentre os documentos elencados na Consolidação, é a que traz referências mais explícitas quanto à presença das pessoas com deficiência na educação profissional. Ainda que focada, sobretudo, em questões de acessibilidade arquitetônica,

\begin{tabular}{|l|l|l|}
\hline v.11 & n.3
\end{tabular}


apresenta reflexões sobre os processos que podem concretizar a inclusão dessas pessoas nos processos formativos. Destaca, dentre os recursos de acessibilidade, a oferta de tradução e interpretação da Língua Brasileira de Sinais, equipamentos de tecnologia assistiva e materiais pedagógicos acessíveis, cuja demanda deverá ser provida pelas instituições da Rede Federal de Educação Profissional, à medida que são apresentadas pelos estudantes matriculados, ou nos processos de seleção para o ingresso. O provimento das condições de pleno acesso e permanência é de responsabilidade da gestão da Rede Federal, e os custos das condições de acessibilidade deverão integrar o planejamento orçamentário das instituições.

O programa Educação, Tecnologia e Profissionalização para Pessoas com Necessidades Educacionais Especiais (TEC NEP) foi criado em 2000, numa parceria entre a Secretaria de Educação Especial (Seesp) e a Secretaria de Educação Profissional e Tecnológica à época. O programa foi concebido para apoiar a Rede Federal de Educação Profissional, Científica e Tecnológica no atendimento ao público alvo da educação especial matriculado em cursos de nível básico, técnico e tecnológico, e cursos de habilitação ou reabilitação para atividades laborais. (BRASIL, 2004). O programa pretendia ampliar a oferta de educação profissional, acesso e permanência no trabalho para as pessoas com deficiência. Dentre as ações do programa, destacamos a criação dos Núcleos de atendimento às pessoas com necessidades especiais (Napne), que atuariam na articulação dos agentes administrativos na promoção de acessibilidade e inclusão dos estudantes com deficiência matriculados nos espaços educativos. Os resultados das ações do programa ainda são pouco conhecidos e, segundo Anjos (2006), há pouca abrangência, visto que o número de matrículas de pessoas com deficiência é ainda pouco expressivo, a instalação de Napne nas instituições não configura necessariamente transposição de barreiras arquitetônicas e atitudinais por parte dos agentes envolvidos.

No texto das Diretrizes Curriculares Nacionais para a Educação Profissional Técnica de Nível Médio constam referências importantes para a educação Profissional do público-alvo da Educação Especial, tendo por base a Política Nacional de Educação Especial na Perspectiva da Educação Inclusiva (2008), a Resolução CNE/CEB no 4/09, que define as Diretrizes Operacionais para o Atendimento Educacional Especializado na Educação Básica e a Convenção sobre os Direitos das Pessoas com Deficiência e seu Protocolo Facultativo (Decreto 6.949/09). Portanto, o texto traz recomendações para a formação dessas pessoas condizentes com os princípios de uma educação inclusiva ao defender a "adoção de medidas políticas educacionais para a acessibilidade e o pleno acesso aos espaços comuns de ensino e

\begin{tabular}{|l|l|l|l} 
& v.11 & n.3 \\
\hline
\end{tabular}


aprendizagem", como também a recomendação de não restringir o acesso aos cursos de formação profissional, em virtude da deficiência. Orienta ainda que as instituições que ofertam a Educação Profissional e Tecnológica devam fazer constar nos seus projetos pedagógicos a concepção de educação inclusiva, a fim de garantir a todos es estudantes respostas às suas necessidades educacionais (BRASIL, 2010).

\section{CONSIDERAÇÕES FINAIS}

Não há como dissociar o tratamento dado à questão da Educação Profissional da pessoa com deficiência do modo como as relações de produção são estabelecidas. Em síntese, é possível afirmar que:

- $\quad \mathrm{Na}$ Política Nacional de Educação Especial na perspectiva da Educação Inclusiva, a questão da Educação Profissional é mencionada como uma modalidade de educação que será contemplada pelo atendimento educacional especializado, com a finalidade de ampliar as "oportunidades de escolarização, formação para ingresso no mundo do trabalho e efetiva participação social" (BRASIL, 2008).

- Não há muitos programas, documentos, diretrizes específicas sobre a educação profissional da pessoa com deficiência, com exceção do TEC NEP, em 2000, e do documento da Secretaria de Educação Especial de 2003. Ainda assim, há que se ressaltar que o referido programa precisa ser analisado, a fim de investigar suas possibilidades e viabilidades com relação aos estudantes com deficiência.

- O Parecer Técnico n¹9/2011 (MEC/Seesp/Dpee) manifesta-se sobre o Projeto de Lei $n^{\circ} 7.699 / 2006$, que institui o Estatuto do portador de deficiência, aprovado finalmente em 2011. Faz críticas à Educação Profissional proposta no referido Estatuto, pois contraria as diretrizes previstas na legislação vigente sobre a Educação Especial. A previsão da modalidade em ambiente segregado, por exemplo, reduz as possibilidades de inserção dos estudantes com deficiência em ambientes produtivos, ou em espaços reais do mundo do trabalho. Quanto ao direito à acessibilidade, o Estatuto prevê que as instituições de educação profissional "se adequem" ou "se flexibilizem". Prevê, como proposta e atendimento e formação profisssional as chamadas "oficinas protegidas terapêuticas", que também restringem a participação dos estudantes com deficiência a ambientes segregados e que não promovem práticas inclusivas (BRASIL, 2016). 
- Um dos únicos documentos encontrados em que há interlocução entre Educação Profissional e Educação Especial é a Nota Técnica no. 106/2013, que apresenta a orientação a implementação da política institucional de acessibilidade na Rede Federal de Educação Profissional, Científica e Tecnológica. O texto ressalta que a acessibilidade para as pessoas com deficiência ou com mobilidade reduzida é uma garantia constitucional, reafirmada em portarias, decretos, resoluções, e ainda apresenta a Rede Federal de Educação Profissional e Tecnológica e o Pronatec como ações que também são promotoras de inclusão de pessoas com deficiência. Aponta que o novo paradigma da inclusão, ao tornar-se realidade na vida das pessoas, promove a efetividade de direito à educação e um sistema público de ensino inclusivo.

Da leitura de documentos que orientam a Educação Especial, a Educação Profissional e o Ensino Médio, não foi possível encontrar interfaces entre essas modalidades de Educação, tampouco políticas públicas de educação profissional específicas para a população com deficiência. Mesmo nos levantamentos estatísticos há uma visível discrepância entre as informações apresentadas e a realidade dessa parcela importante da população brasileira, como aponta Clemente (2015). Percebemos, a partir dessas constatações, que há um processo de invisibilização da população brasileira com deficiência, percebido tanto nessa ausência de políticas públicas interligadas, como na ausência dessas pessoas no mundo do trabalho. A legislação do país garante, há quase duas décadas, as vagas para essas pessoas nas empresas, mas não há, no campo das políticas educacionais, programas que fomentem a formação e o acesso da população com deficiência a esse direito.

Diante desse contexto, impõe-se o desafio de continuar. Continuar a discussão como uma forma de resistência. Aprofundar o estudo do campo da Educação Profissional de pessoas com deficiência, posicionando-se criticamente, repensando práticas educativas, pautando-se pelos princípios da dignidade da pessoa humana. Impõe-se também o questionamento dos modos de produção no capitalismo, se o que se quer, de fato, comprometer-se com a fruição do direito social ao trabalho como uma experiência universal. Assim, sugere-se, para possíveis novas pesquisas, que seja incorporada a temática das alternativas ao modo de produção estabelecido pelo capitalismo. São formas produtivas alternativas à economia do mercado competitivo que promovem a abordagem solidária e cooperativa. A solidariedade na economia só pode se realizar se ela for organizada igualitariamente pelos que se associam par produzir, comerciar, consumir ou poupar. A chave 
da referida proposta é a associação entre iguais, em vez do contrato entre desiguais. A economia solidária implica outro modo de produção, cujos princípios básicos são a propriedade coletiva ou associada do capital e o direito à liberdade individual. A aplicação desses princípios une todos os que produzem numa única classe de trabalhadores que são possuidores de capital por igual em cada cooperativa ou sociedade econômica.

Pensar outras formas de inserção na produção, outra relação com o Trabalho, tomando-o como direito social de contribuir na transformação da realidade, e não como emprego, são elementos fundamentais a serem pesquisados para que se rompa com a lógica assistencialista e reabilitadora que parece, ainda hoje, predominar na Educação Profissional ofertada a pessoas com deficiência.

[...] apesar de seu excesso de riqueza, a sociedade civil não é assaz rica, isto é, que dentro de sua riqueza, ela não possui bens suficientes para pagar o tributo ao excesso de miséria e à plebe que ela mesmo [sic] engendra. (HEGEL; KAAN, 1940, p. 262).

\section{REFERÊNCIAS}

BRASIL. Convenção Internacional sobre os Direitos da Pessoa com Deficiência e seu Protocolo Facultativo. Decreto Legislativo n 186, de 9 de julho de 2008.

BRASIL. Lei 11.741, de 16 de julho de 2008. Altera dispositivos da Lei $n^{0}$ 9.394, de 20 de dezembro de 1996, que estabelece as diretrizes e bases da educação nacional, para redimensionar, institucionalizar e integrar as ações da educação profissional técnica de nível médio, da educação de jovens e adultos e da educação profissional e tecnológica. Diário Oficial da União, v. 136, 2008.

BRASIL. Lei $\mathbf{n}^{\circ}$ 12.513, de 26 de outubro de 2011. Institui o Programa Nacional de Acesso ao Ensino Técnico e Emprego (Pronatec). Diário Oficial da União, 2011.

BRASIL. Lei $\mathbf{n}^{\circ}$ 13.146, de 06 de julho de 2015. Institui a Lei Brasileira de Inclusão da Pessoa com Deficiência (Estatuto da Pessoa com Deficiência). Diário Oficial da União, 2015.

BRASIL. Decreto n. 5.154, de 23 de julho de 2004. Regulamenta o $\S 2^{\circ}$ do art. 36 e os arts. 39 a 41 da Lei $n^{\circ}$ 9.394, de 20 de dezembro de 1996, que estabelece as diretrizes e bases da educação nacional, e dá outras providências. Diário Oficial da União, 2004.

BRASIL. Decreto $\mathbf{n}^{\circ}$ 5.478, de 24 de junho de 2005. Institui, no âmbito das instituições federais de educação tecnológica, o Programa de Integração da Educação Profissional ao Ensino Médio na Modalidade de Educação de Jovens e Adultos-PROEJA. Brasília, DF, v. 24, 2005. 
BRASIL. Decreto $\mathbf{n}^{\mathbf{0}}$ 9.005, de 14 de março de 2017. Aprova a Estrutura Regimental e o Quadro Demonstrativo dos Cargos em Comissão e das Funções de Confiança do Ministério da Educação, remaneja cargos em comissão e substitui cargos em comissão do Grupo-Direção e Assessoramento Superiores - DAS por Funções Comissionadas do Poder Executivo FCPE. Diário Oficial da União, 2017.

BRASIL. Consolidação da Inclusão Escolar no Brasil - 2003 a 2016. Brasília, DF, 2016.

BRASIL. Resolução $\mathbf{n}^{\circ} \mathbf{1}$, de 03 de fevereiro de 2005. Atualiza as Diretrizes Curriculares Nacionais definidas pelo Conselho Nacional de Educação para o Ensino Médio e para a Educação Profissional Técnica de nível médio às disposições do Decreto $n^{0}$ 5.154/2004. Diário Oficial da União, de 11 de março de 2005, Seção 1, p. 9

BRASIL. Resolução $\mathbf{n}^{0}$ 6, de 20 de setembro de 2012. Define Diretrizes Curriculares Nacionais para a Educação Profissional Técnica de Nível Médio. Resolução CNE/CEB 6/2012. Diário Oficial da União, Brasília, 21 de setembro de 2012, Seção 1, p. 22

BRASIL. Ministérios da Educação. Educação profissional-indicações para ação: a interface educação profissional/educação especial. Brasília: MEC/SEESP, 2003.

BRASIL. Ministério da Educação. Plano de Desenvolvimento da Educação: razões, princípios e programas (PDE). Brasília, DF, 2007.

BRASIL. Ministério da Educação. Política Nacional de Educação Especial na Perspectiva da Educação Inclusiva. Brasília, DF, 2008.

BRASIL. Ministério da Educação. Secretaria de Educação Continuada, Alfabetização, Diversidade e Inclusão. Diretoria de Políticas de Educação Especial. Nota Técnica $\mathbf{n}^{\mathbf{0}}$ 055, de 10 de maio de 2013.

BRASIL. Ministério da Educação. Secretaria de Educação Continuada, Alfabetização, Diversidade e Inclusão. Diretoria de Políticas de Educação Especial. Nota Técnica no 101, de 12 de agosto de 2013.

BRASIL. Ministério da Educação. Secretaria de Educação Continuada, Alfabetização, Diversidade e Inclusão. Diretoria de Políticas de Educação Especial. Nota Técnica n 106 de 19 de agosto de 2013.

BRASIL. Cartilha do Censo 2010 - Pessoas com Deficiência. Secretaria de Direitos Humanos da Presidência da República (SDH/PR) / Secretaria Nacional de Promoção dos Direitos da Pessoa com Deficiência (SNPD) / Coordenação-Geral do Sistema de Informações sobre a Pessoa com Deficiência; Brasília: SDH-PR/SNPD, 2012.

BRASIL. Censo Demográfico 2010 - características gerais da população, religião e pessoas com deficiência. IBGE, 2012.

CASTIONI, R.; ANDRADE, M.C.C. Mudanças do marco institucional da educação profissional: uma leitura a partir dos dados do censo escolar. Brasília, DF: Linhas Críticas, 2010. V. 16, n. 30, p. 109-128, jan./jun. 2010. ISSN 1516-4896.

\begin{tabular}{|l|l|l|l|}
\hline v.11 & n.3 \\
\hline
\end{tabular}


CLEMENTE, C.A. Lei de Cotas para o trabalho de pessoas com deficiência - análise e fundamentação dos principais argumentos favoráveis e contrários ao seu cumprimento. (TCC). Escola Dieese de Ciências do Trabalho. São Paulo, 2015.

FRIGOTTO, G.; CIAVATTA, M.; RAMOS, M. A política de educação profissional no governo Lula: um percurso histórico controvertido. Campinas, Educ. Soc., v. 26, n. 92, p. 1087-1113, Especial, Out. 2005.

GODOI, J.; CAMPOS, R. A relação público-privado que se estabelece no Pronatec no ensino médio profissionalizante. Revista Roteiro, Joaçaba, Edição Especial, p. 183-204. 2014.

HEGEL, G.W.F.; KAAN, A. Principes de la philosophie du droit. 1940.

KUENZER, A. Da dualidade assumida à dualidade negada: o discurso da flexibilização justifica a inclusão excludente. Educação \& Sociedade, v. 28, n. 100, 2007.

LANCILLOTTI, S.S.P., Deficiência e Trabalho: Redimensionando o Singular no Contexto Universal. Campinas, SP: Autores Associados, 2003.

OLIVEIRA, R. Precarização do trabalho: a funcionalidade da educação profissional. Revista Diálogo Educacional, v. 15, n. 44, 2015.

PINO, M. D. Política Nacional, emprego e exclusão social. In: A cidadania negada políticas de exclusão na educação e no trabalho. 2000. 